\title{
IMPLEMENTASI PROGRAM KELUARGA HARAPAN DI KECAMATAN TAMALATE KOTA MAKASSAR
}

\author{
Clara Dheby ${ }^{1}$, Abdul Kadir Adys², Muhammad Idris ${ }^{3}$ \\ ${ }^{1)}$ Program Studi Ilmu Administrasi Negara Unismuh Makassar \\ ${ }^{2}$ Program Studi Ilmu Administrasi Negara Unismuh Makassar \\ 3)Program Studi Ilmu Administrasi Negara Unismuh Makassar
}

\begin{abstract}
The objective of this research is to know the implementation of expectation family program In Tamalate sub-district of Makassar City. This research is qualitative and the type is phenomenology. The data is obtained by interview, observation, and documentation. The source of data is primary and secondary data. The informant involved in this research is ten informants. A technique of data analysis pervades reduction of data, presentation of data, conclusion, and verification. The legality of data pervades source triangulation, technical triangulation, and time triangulation.The result of this research reveals that Expectation Family Program in health field in Tamalate subdistrict has applied digital financial service and health facility providing well. The Expectation Family Program in education field of Tamalate sub-district is not maximal yet, in particular on activation of illiterate children and home providing.
\end{abstract}

Keywords : Implementation of policy, Expectation Family Program

\begin{abstract}
ABSTRAK
Tujuan penelitian ini adalah untuk mengetahui implementasi Program Keluarga Harapan di Kecamatan Tamalate Kota Makassar. Jenis penelitian adalah kualitatif dan tipe penelitian adalah fenomenologi. Data diperoleh melalui wawancara, observasi dan dokumentasi. Sumber data penelitian adalah data primer dan sekunder. Jumlah informan penelitian adalah 10 orang. Teknik analisis data meliputi reduksi data, penyajian data serta penarikan kesimpulan dan verifikasi. Pengabsahan data meliputi triangulasi sumber, triangulasi teknik dan triangulasi waktu. Hasil penelitian menujukkan bahwa PKH bidang kesehatan di Kecamatan Tamalate telah melaksanakan dengan baik layanan keuangan digital dan penyediaan fasilitas kesehatan. PKH bidang pendidikan di Kecamatan Tamalate belum memaksimalkan Pengentasan anak buta huruf dan penyediaan rumah singgah.
\end{abstract}

Kata kunci : Implementasi Kebijakan, Program Keluarga Harapan (PKH) 


\section{PENDAHULUAN}

Program Keluarga Harapan (PKH) merupakan program yang dikeluarkan pemerintah Indonesia melalui kementrian sosial untuk meminimalisir permasalahan kesejahteraan sosial, khusunya masalah kemiskinan.

PKH berfokus pada dua komponen yang berkaitan dengan komponen peningkatan kualitas sumber daya manusia yaitu pada bidang kesehatan dan pendidikan.

Kesehatan merupakan kunci untuk melakukan aktifitas dan pendidikan yang layak maka secara otomatis akan meningkatkan kualitas sumberdaya manusia. Namun perlu disadari bahwa tidak semua rakyat bisa mendapatkan pelayanan kesehatan dan pendidikan yang layak, lapisan masyarakat menengah kebawah banyak yang tidak bisa merasakan pelayanan kesehatan dan mengenyam pendidikan. Hal ini di karenakan mereka tidak memiliki biaya untuk mengakses kesehatan dan pendidikan.

Angka kesehatan masyarakat miskin yang masih rendah diakibatkan karena sulitnya akses terhadap pelayanan kesehatan. Kesulitan akses pelayanan dipengaruhi oleh berbagai faktor seperti tidak adanya kemampuan secara ekonomi karena biaya pengobatan penyakit yang relatif mahal. Bagi warga miskin untuk mendapatkan pelayanan kesehatan yang memuaskan adalah hal yang sangat sulit.

Buruknya layanan kesehatan masih menjadi keluhan masyarakat yang kurang mampu di Indonesia. Upaya pemerintah untuk memberikan pelayanan kesehatan terhadap warga miskin melalui JAMKESMAS masih belum dapat terealisasikan dengan baik.

Mahalnya biaya pendidikan di Indonesia memaksa keluarga miskin untuk tidak menyekolahkan anakanaknya. Banyak anak-anak usia 612 tahun putus sekolah dan memilih untuk mencari pekerjaan untuk memenuhi kebutuhan hidup kedepannya. Meskipun telah banyak strategi untuk meningkatkan akses sekolah seperti beasiswa miskin, bantuan operasional sekolah (BOS) akan tetapi angka partisipasi sekolah 
masih belum optimal terutama bagi anak-anak KPM.

Maka dari itu PKH memberikan peluang yang lebih baik dalam mengakses pelayanan kesehatan dan pendidikan yang layak. Berdasarkan surat Keputusan Kementrian Sosial Republik Indonesia No. 1293 tahun 2016 tentang Reorganisasi Pelaksana PKH Pusat dan Daerah, PKH dialokasikan ke daerah - daerah yang telah memenuhi syarat yang ditentukan.

Khusus untuk kota Makassar, jumlah penerima PKH pada tahun 2015 berjumlah 9116 KPM yang tersebar di 12 kecamatan, yaitu kecamatan biringkanaya, Bontoala, Makassar, Mamajang, Manggala, Mariso, Panakkukang, Rappocini, Tallo, Tamalanrea, Tamalate dan Ujung Tanah.

Kecamatan Tamalate memiliki jumlah masyarakat miskin atau KPM paling banyak diantara kecamatan lainnya. Hal itu disebabkan wilayah ini merupakan wilayah perbatasan. Jumlah KPM yang terdaftar dalam peserta PKH di kecamatan Tamalate, yaitu 2.183 KPM. Implementasi atau penerapan yang baik akan berdampak pada hasil program yang akan dilaksanakan.

Implementasi yang baik dari program keluarga harapan diharapkan juga mampu mengurangi kemiskinan dengan cara meningkatkan sumber daya manusia pada kelompok masyarakat miskin di bidang kesehatan dan pendidikan.Program ini telah dilaksanakan sejak tahun 2010, namun pada kenyataannya jumlah KPM di Kecamatan Tamalate Kota Makassar terus meningkat. Pada tahun 2015 sejumlah 2183 KPM dan pada tahun 2016 sejumlah 2554 KPM, ini berarti jumlah KPM pada tahun 2015-2016 bertambah sebanyak 371 KPM. Terkait dengan diberlakukannya PKH di kecamatan Tamalate maka perlu ada koordinasi dari pihak terkait, agar dalam pelaksanaannya dapat menjaring kelompok sasaran yang tepat dan dapat berjalan sesuai dengan rencana.

Kebijakan publik merupakan kewenangan pemerintah menjalankan tugas dan fungsinya dalam hubungannya dengan masyarakat dan dunia usaha. Pada dasarnya kebijakan 
pemerintah dalam menata kehidupan masyarakat diberbagai aspek merupakan kebijakan yang berorientasi pada kepentingan publik. Pengertian kebijakan adalah prinsip atau cara bertindak yang dipilih untuk mengarahkan pengambilan keputusan. Dalam setiap penyusunan kebijakan publik diawali oleh perumusan masalah yang telah diidentifikasi kemudian pelaksanaan kebijakan tersebut ditujukan untuk mengatasi masalah yang terjadi dalam masyarakat (Mustari, 2015: 1).

Salah satu definisi mengenai kebijakan publik diberikan oleh Robert Eyestone (Winarno, 2012:20), ia mengatakan bahwa secara luas kebijakan publik dapat didefinisikan sebagai hubungan suatu unit pemerintah dengan lingkungannya. Konsep yang ditawarkan Eyestone ini mengandung pengertian yang sangat luas dan kurang pasti karena apa yang dimaksud dengan kebijakan publik dapat mencakup banyak hal.

Menurut Salusu (Mustari, 2013:129), implementasi adalah seperangkat kegiatan yang dilakukan menyusul satu keputusan. Suatu keputusan selalu dimaksudkan untuk mencapai sasaran, guna merealisasikan pencapaian sasaran tersebut, diperlukan serrangkaian aktivitas. Jadi dapat dikatakan bahwa implementasi adalah operasionalisasi dari berbagai aktivitas guna mencapai sasaran tertentu.

Implementasi kebijakan menurut William N. Dunn (2003: 132) "Implementasi adalah pelaksanaan pengendalian aksi-aksi kebijakan di dalam kurun waktu tertentu". Menurut Joko Widodo (2007: 88) “implentasi kebijakan merupakan proses usaha untuk mewujudkan suatu kebijakan yang masih bersifat abstrak kedalam realita nyata". Jadi implementasi kebijakan merupakan suatu wujud nyata dari kebijakan yang telah dilaksanakan dalam kurun waktu yang telah ditentukan.

Agar kebijakan implementatif, maka dikenal beberapa pendekatan. Secara teoritik empirik, pendekatanpendekatan ini dinggap memadai sebagai alat bantu atau penguatan untuk keberhasilan implementasi kebijakan. Walau dari berbagai pendekatan praktiknya membutuhkan pertimbangan komperehensif 
sehingga pendekatan yang dipilih, diadaptasi atau mungkin bahkan dikimbinasi adalah teknis sesuai kebutuhan. Untuk kepentingan implementasi kebijakan, bukan merupakan monopoli secara liniear dari hanya para ahli kebijakan saja. Tetapi bisa diadopsi dari para ahli ilmu-ilmu sosial lain, baik dari pakar ilmu politik, pakar organisasi dan manajemen maupun dari para ahli lainnya. Dengan kata lain untuk kepentingan implementasi kebijakan dibutuhkan pendekatan dan ilmu yang komprehensif sejalan dengan yang dikemukakan Nicolas Henry (Mustari, 2015:141) yaitu pendekatan politik, pendekatan struktural, pendekatan prosedur dan managerial dan pendekatan perilaku.

Menurut Goggin et al. (Purwanto \& Sulistyastuti, 2012:89), kebijakan diasumsikan sebagai suatu "pesan" dari pemerintah federal (pusat) kepada pemerintah daerah. Keberhasilan implementasi pesan tersebut sangat dipengaruhi oleh 3 hal pokok yaitu isi kebijakan (the content of the policy message), format kebijakan (the form of the policy message)dan reputasi aktor (the reputation of the communicators). Menurut Edward III, ada empat variabel yang sangat mempengaruhi keberhasilan kebijakan yaitu komunikasi, sumber daya, disposisi dan komunikasi.

Mazmanian dan Sabatier mendefinisikan implementasi sebagai upaya melaksanakan keputusan kebijakan. Menurut model ini, yang mempengaruhi implementasi kebijakan dapat diklasifikasikan ke dalam tiga variabel, yaitu (Nugroho, 2008) yaitu : (a) variabel independen yaitu mudah tidaknya masalah dikendalikan yang berkenaan dengan indikator masalah teori dan teknis pelaksanaan, keragaman objek dan perubahan seperti apa yang dikehendaki. (b) Variabel interveningyaitu variabel kemampuan kebijakan untuk menstrukturkan proses implementasi dengan indikator kejelasan dan konsistensi tujuan. (c) variabel dependen yaitu variabelvariabel yang mempengaruhi proses implementasi yang berkenaan dengan indikator kondisi sosial ekonomi dan teknologi, dukungan publik, sikap dan risorsis konstituen, dukungan pejabat yang lebih tinggi dan 
komitmen dan kualitas kepemimpinan dari pejabat pelaksana.

Joan L.Herman dan Cs, yang dikutip oleh Farida Yusuf Tayibnapis (2008:

9) mengemukakan definisi program sebagai berikut : "Program ialah segala sesuatu yang coba dilakukan oleh seseorang dengan harapan akan mendatangkan hasil atau pengaruh".

Hasibuan

(2006:72)

mengungkapkan bahwa definisi program adalah sebagai berikut: "Program adalah suatu jenis rencana yang konkret karena di dalamnya sudah tercantum sasaran, kebijaksanaan, prosedur, anggaran, dan waktu pelaksanaan".

Program Keluarga Harapan (PKH) adalah program perlindungan sosial yang memberikan bantuan tunai kepada Keluarga Penerima Manfaat (KPM) dan bagi anggota keluarga KPM diwajibkan melaksanakan persyaratan dan ketentuan yang telah ditetapkan.

Program ini dalam jangka pendek bertujuan mengurangi beban KPM dan dalam jangka panjang diharapkan dapat memutus mata rantai kemiskinan antar generasi, sehingga generasi berikutnya dapat keluar dari perangkap kemiskinan. Pelaksanaan PKH juga mendukung upaya pencapaian Tujuan Pembangunan Millenium. Lima komponen Tujuan MDG's yang akan terbantu oleh PKH yaitu: Pengurangan penduduk miskin dan kelaparan, Pendidikan dasar, Kesetaraan Gender, Pengurangan angka kematian bayi dan balita, serta Pengurangan kematian ibu melahirkan.

Penerima bantuan PKH adalah Keluarga Penerima Manfaat (KPM) yang memiliki anggota keluarga yang terdiri dari anak usia 0-15 tahun (atau usia 15-18 tahun namun belum menyelesaikan pendidikan dasar) dan/atau ibu hamil/nifas.

PKH memberikan bantuan tunai kepada KPM dengan mewajibkan KPM tersebut mengikuti persyaratan yang ditetapkan program, yaitu: (1) menyekolahkan anaknya di satuan pendidikan dan menghadiri kelas minimal $85 \%$ hari seekolah/tatap muka dalam sebulan selama tahun ajaran berlangsung, dan (2) melakukan kunjungan rutin ke 
fasilitas kesehatan bagi anak usia 0-6 tahun, ibu hamil dan ibu nifas.

\section{METODE PENELITIAN}

Penelitian ini dilakukan selama 2 bulan dimulai dari bukan februari sampai dengan bulan maret. Lokasi penelitian dilakukan di Dinas Sosial Kota Makassar dan Kecamatan Tamalate Kota Makassar, dengan pertimbangan Dinas Sosial Kota Makassar merupakan pelaksana PKH di Kota Makassar dan Kecamatan Tamalate merupakan Kecamatan yang memiliki jumlah KPM terbanyak di Kota Makassar.

Disertai dengan pertimbangan bahwa melakukan penelitian mengenai implementasi Program Keluarga Harapan adalah untuk mengetahui implementasi Program Keluarga Harapan (PKH) bidang pendidikan dan mengetahui implementasi Program Keluarga Harapan (PKH) bidang kesehatan di Kecamatan Tamalate Kota Makassar.

Jenis penelitian yang digunakan dalam penelitian ini adalah penelitian kualitatif yang berusaha menjelaskan sedetil mungkin objel dan masalah penelitian berdasarkan fakta yang diperoleh dilapangan mengenai implementasi Program Keluarga Harapan di Kecamatan Tamalate Kota Makassar. Tipe penelitian yang digunakan dalam penelitian adalah fenomenologi yang merupakan bentuk penelitian yang bertujuan untuk memberikan gambaran umum berbagai macam data yang dikumpul dari lapangan secara objektif berdasarkan fenomena-fenomena yang terjadi berdasarkan pengalaman hidup seseorang.

Adapun sumber data yang digunakan terbagi atas 2 yaitu data primer dengan menggunakan wawancara sejumlah orang yang berkaitan dengan implementasi Program Keluarga Harapan di Kecamatan Tamalate Kota Makassar dan data sekunder dengan mengumpulkan berupa dokumen ataupun laporan tertulis yang berkaitan dengan implementasi Program Keluarga Harapan.

Jumlah informan pada penelitian ini sebanyak10 orang informan yang terdiri dari Kepala Seksi Jaminan Kesejahteraan Sosial Dinas Sosial Kota Makassar, Kepala Seksi Pemberdayaan Masyarakat dan 
Kesejahteraan Sosial Kecamatan Tamalate, Koordinator Pendamping Kota Makassar, Koordinator Pendamping Kecamatan Tamalate, Pendamping PKH Kecamatan Tamalate dan Peserta PKH sebanyak 5 orang. Dalam penelitian, pengumpulan data dilakukan melalui beberapa teknik diantaranya wawancara mendalam, observasi dan dokumentasi.

\section{HASIL DAN PEMBAHASAN}

Program Keluarga Harapan (PKH) berfokus pada dua komponen yang berkaitan dengan peningkatan kualitas sumber daya manusia yaitu pada bidang kesehatan dan pendidikan.

Peneliti mencoba untuk melihat implementasi Program Keluarga Harapan bidang kesehatan dan Bidang kesehatan dengan mengacu pada dua variabel yang mempengaruhi keberhasilan implementasi menurut Grindle (Nugroho, 2012) yaitu Variabel isi kebijakan dan Variabel lingkungan kebijakan.

$$
\text { Pelayanan kesehatan }
$$

merupakan hak setiap orang yang dijamin dalam Undang-Undang Dasar Negara Republik Indonesia tahun 1945 yang harus diwujudkan dengan upaya peningkatan derajat derajat kesehatan masyarakat yang stinggitingginya. Mengingat hal itu, Program Keluarga Harapan mencoba memberi solusi kepada masyarakat tidak mampu agar dapat mengakses fasilitas kesehatan yang layak berupa Pemberian Langsung Tunai dan penyediaan fasilitas kesehatan berupa Puskesmas, Pustu, Posyandu dan Bidan.

bahwa keberadaan Program Keluarga Harapan bidang kesehatan tidak lain adalah untuk meningkatkan kualitas kesehatan masyarakat miskin. Dalam sudut pandang implementasi Program dengan menggunakan pendekatan teori model Grindle (Nugroho,2012), PKH telah hadir menjadi solusi mengenai susahnya masyarakat miskin untuk mengakses layanan kesehatan. Setelah adanya PKH bidang kesehatan ini, masyarakat miskin yang menjadi peserta PKH telah dapat menikmati fasilitas kesehatan berupa Puskesmas, Pustu, Posyandu 
dan bidan tanpa memikirkan biaya yang harus dikeluarkan.

Manfaat yang didapatkan menjadi peserta PKH adalah diberikannya fasilitas kesehatan secara gratis. Program Keluarga Harapan di Kecamatan Tamalate juga telah mampu mengubah pola hidup peserta PKH menjadi lebih sehat. Selain itu, peserta PKH juga mendapatkan bantuan berupa uang tunai yang digunakan untuk memenuhi kebutuhan kesehatan peserta.

Keberadaan Program Keluarga Harapan bidang kesehatan telah sesuai dengan apa yang dikatakan oleh Grindle (Nugroho,2012) bahwa suatu program harus dapat memberikan hasil yang bermanfaat dan berdampak positif serta dapat merubah kearah yang lebih baik dari hasil pengimplementasiannya. Dimana Program Keluarga Harapan telah mampu mengubah pola hidup masyarakat untuk selalu menjaga kesehatan.

Uang tunai yang diberikan kepada peserta PKH setiap tiga bulan sekali diharapkan dapat menerapkan pola hidup sehat masyarakat miskin yang menjadi peserta PKH di Kecamatan Tamalate. Di samping memberikan uang tunai sebagai penunjang dalam menerapkan pola hidup sehat peserta PKH di Kecamatan Tamalate juga diberikan motivasi-motivasi oleh pendamping PKH agar selalu menjaga kesehatan keluarga. Hasil pengamatan yang dilakukan oleh penulis menunjukkan bahwa pada pertemuan mingguan pendamping memberikan motivasimotivasi hidup sehat kepada peserta PKH.

Motivasi-motivasi yang diberikan oleh pendamping $\mathrm{PKH}$ kepada peserta PKH di Kecamatan Tamalate memberikan perubahan terhadap tingkat kesehatan peserta PKH yang di dukung oleh bantuan berupa uang yang diberikan setiap tiga bulan sekali. Perubahan yang terjadi pada peserta PKH bidang kesehatan di Kecamatan Tamalate telah sesuai dengan tujuan $\mathrm{PKH}$ bidangkesehatan yakni meningkatkan kualitas kesehatan peserta PKH.

Program Keluarga Harapan (PKH) merupakan inisiator dari kementrian sosial Republik Indonesia yang merupakan instansi 
pemerintah yang bergerak di bidang sosial. Program ini berupaya untuk mengembangkansistem perlindungan sosial terhadap warga miskin di Indonesia.PKH di jalankan sebagai pelaksanan dari Undang-Undang no.40 tahun 2004 tentang jaminan sosial. Undang-Undang no.11 tahun 2009 tentang kesejahteraan sosial. Perpres no.15 tahun 2010 tentang percepatan penanggulangan kemiskinan dan Undang-Undang no.39 tahun 1999 tentang hak asasi manusia dan Inpres no. 3 tahun 2010 tentang program pembangunan yang berkeadilan. Dinas Sosial menjadi pelaksana program di tingkat kabupaten/kota berdasarkan Surat Keputusan Kementrian Sosial Republik Indonesia No. 1293 tahun 2016 tentang Reorganisasi Pelaksana PKH Pusat dan Daerah.

Pelaksanaan PKH bidang kesehatan, tidak ada LSM yang bergerak untuk membantu pelaksanaan PKH di Kecamatan Tamalate. Dengan diberikan bimbingan dan pelatihan teknis terlebih dahulu, pendamping PKH di Kecamatan Tamalate diberikan kepercayaan untuk melakukan pendampingan langsung kepada peserta PKH. Selain pendamping PKH adalah orang-orang yang dianggap mampu, PKH bidang kesehatan juga bekerja sama dengan instansi-instansi kesehatan di Kecamatan Tamalate.

Pada tahap pelaksanaan di daerah, yang menjadi pelaksana $\mathrm{PKH}$ adalah Dinas Sosial yang kemudian bekerjasama dengan Dinas Kesehatan (untuk bidang kesehatan) serta beberapa stakeholders lainnya. Adapun kedudukan penyuluh atau pendamping yaitu sebagai mediator bahkan dapat menjadi motivator, agar tumbuh kesadaran dari peserta PKH tentang arti pentingnya hidup sehat. Hal ini dibuktikan pada saat melakukanpertemuan, pendampinglah yang menjadi penanggung jawab sepenuhnya.

Selain pendamping, puskesmas dan bidan juga merupakan sumberdaya penunjang keberhasilan PKH di Kecamatan Tamalate. Dari hasil observasi peneliti di lapangan, menemukan bahwa kondisi infrastruktur dan layanan alat-alat kesehatan di beberapa Puskesmas di Kecamatan Tamalate sudah baik. 
Empat Puskesmas yang ada di Kecamatan Tamalate dalam kondisi baik dan bersih. Lain lagi masalah sumberdaya manusia seperti kondisi Bidan dan pamong (petugas pelayana puskesmas). Idealnya suatu pelayanan adalah ketika pelayan atau pamong, mampu bersikap profesional. Tetapi, dari pantauan pengamatan peneliti menemukan kondisi pelayanan yang belum ramah terhadap masyarakat. Pelayanan Kesehatan di taraf Puskesmas Tamalate saat ini masih sering dikeluhkan oleh masyarakat.

Pelaksanaan Program Keluarga Harapan (PKH) bidang kesehatan melibatkan beberapa aktor demi kelancaran pelaksanaan PKH bidang kesehatan di Kecamatan Tamalate. Beberapa aktor yang terlibat dalam pelaksanaan PKH adalah Dinas Sosial, Pendamping PKH, Dinas Kesehatan, dan PT.POS/BRI.

Seperti yang telah dijelaskan sebelumnya bahwa Dinas Sosial dan pendamping PKH Kecamatan Tamalate adalah aktor yang berperan penting dalam pelaksanaan PKH di Kecamatan Tamalate. Sebagai pelaksana $\mathrm{PKH}$, untuk bidang kesehatan, Dinas Sosial yang salah satu fungsinya adalah melakukan koordinasi dengan insitansi terkait, melakukan kerjasama dengan Dinas Kesehatan untuk menyediakan fasilitas kesehatan. Seperti pelayanan dan pengobatan gratis di Puskesmas. Pendamping $\mathrm{PKH} \quad \mathrm{di}$ Kecamatan Tamalate dalam melakukan verifikasi kesehatan peserta PKH di Puskesmas atau posyandu. Dalam sudut pandang implementasi Program dengan menggunakan pendekatan teori model Grindle (Nugroho,2012) karakteristik lembaga pelaksana PKH bidang kesehatan telah berjalan dengan baik dimana stakeholders telah bekerja sesuai dengan tugasnya masing-masing. Serta terjalin kerja sama yang baik antara pelaksana program dengan instansi terkait sehingga proses verifikasi data peserta PKH berjalan dengan lancar.

Kepatuhan dan daya tanggap juga merupakan bagian penting dari proses implementasi suatu kebijakan, dimana tingkat kepatuhan dan adanya respon dari para pelaksana kebijakan merupakan aksi nyata dari para pelaksana untuk melaksanakan 
tugas pokok dan fungsinya dalam pengimplementasian Program Keluarga Harapan (PKH) bidang kesehatan agar dapat terlaksana dengan baik secara optimal dan berdaya guna. Maka berkaitan dengan hal tersebut, ada beberapa aturan serta mekanismenya dari setiap instansi dalam melaksanakan tugasnya.

\section{Pelaksanaan Program Keluarga} Harapan (PKH) bidang kesehatan ini tentunya terkoordinasi dengan baik dari tingkat pusat, provinsi, kabupaten/kota serta tingkat unit masyarakat atau tingkat kecamatan. tingkat kepatuhan dan daya tanggap pelaksana dan peserta PKH bidang kesehatan di Kecamatan Tamalate cukup baik. Ini dilihat dari kinerja pendampig PKH yang telah sesuai dengan pedoman PKH bidang kesehatan.

\section{Implementasi Program}

Keluarga Harapan (PKH) bidang kesehatan di Kecamatan Tamalate berjalan dengan baik meskipun ada beberapa faktor yang mengganggu kenyamanan peserta $\mathrm{PKH}$ dalam mengakses layanan kesehatan di Kecamatan Tamalate yakni sikap dari pelayan kesehatan yang terkadang bersikap acuh kepada peserta PKH. Namun hal tersebut tidak memberi pengaruh besar terhadap pelaksanaan Program Keluarga Harapan (PKH) bidang kesehatan dalam memberikan pelayanan kesehatan kepada peserta PKH guna untuk meningkatkan taraf kesehatan dan menerapkan pola hidup sehat KPM di Kecamatan Tamalate.

Pendidikan adalah serangkaian usaha untuk mengembangkan bangsa. Pengembangan bangsa itu akan dapat diwujudkan secara nyata dengan usaha menciptakan ketahanan nasional dalam rangka mencapai cita-cita bangsa. Tujuan pendidikan dalam Undang-Undang No.20 tentang Sistem Pendidikan Nasional Pasal 3 adalah mengembangkan potensi peseta didik agar menjadi manusia yang beriman dan bertakwa kepada Tuhan Yang Maha Esa, berakhlak mulia, sehat, berilmu, cakap, kreatif, mandiri dan menjadi warga negara yang demokratis serta betanggung jawab.

PKH bidang pendidikan hadir menjadi solusi untuk anak-anak 
Indonesia yang tidak mampu penyediaan rumah belajar dan mengenyam pendidikan. PKH mediasiasi anak untuk mendaftar ke memberikan fasilitas untuk dapat pendidikan formal, nonformal dan mengakses pendidikan berupa pendidikan luar sekolah. Manfaat layanan keuangan digital, besar akan dapat dirasakan oleh pengentasan anak buta huruf, masyarakat apabila Program penyediaan rumah belajar dan Keluarga Harapan (PKH) bidang mediasiasi anak untuk mendaftar ke pendidikan formal, nonformal dan pendidikan luar sekolah.

Adanya PKH sangat membantu keluarga kurang mampu dalam menyekolahkan anak-anaknya. pendidikan ini dapat diimplementasikan dengan maksimal.

Namun pada kenyataanya tidak adanya fasilitas tempat untuk melakukan program pengentasan Dalam hal ini, PKH memprioritaskan kepentingan pendidikan anak-anak dari keluarga yang tidak mampu. Dalam sudut pandang implementasi Program dengan menggunakan pendekatan teori model Grindle (Nugroho,2012), PKH telah hadir menjadi solusi mengenai sulitnya anak-anak dari keluarga yang tidak mampu untuk mengenyam pendidikan yang layak.

Tujuan dari Program Keluarga Harapan $(\mathrm{PKH})$ bidang pendidikan adalah untuk meningkatkan taraf pendidikan masyarakat kurang mampu dengan memberikan fasilitas berupa layanan keuangan digital, pengentasan anak buta huruf, anak buta huruf dan penyediaan rumah belajar, dapat disimpulkan bahwa manfaat yang seharusnya di rasakan oleh peserta PKH berdasarkan program PKH bidang pendidikan di Kecamatan Tamalate belum sepenuhnya dirasakan oleh peserta dikarenakan mereka tidak diberi wadah.

Derajat perubahan yang diinginkan dalam implementasi Program Keluarga Harapan bidang pendidikan di Kecamatan Tamalate belum tercapai dengan maksimal karena ada beberapa program yang dicanangkan dengan tujuan untuk meningkatkan kualitas pendidikan anak-anak KPM belum dilaksanakan 
di Kecamatan Tamalate Kota Makassar.

Isi sebuah kebijakan akan menunjukkan posisi pengambilan keputusan. Kebijakan dibidang tertentu biasanya diputuskan oleh sejumlah besar unit pengambilan kebijakan, sebaliknya ada kebijakan tertentu yang hanya ditentukan oleh sejumlah kecil unit pengambil kebijakan. Implikasi dari jumlah pengambil keputusan adalah semakin banyak yang terlibat akan semakin menyulitkan di dalam implementasi kebijakannya.

Seperti halnya PKH bidang kesehatan, dalam bidang pendidikan, Dinas Sosial Kota Makassar merupakan pelaksana program di Kota Makassar yang melakukan pengawasan, koordinasi, evaluasi dan monitoring ke pendamping, peserta PKH serta kepada instansiinstansi terkait. Dinas Sosial tidak turun langsung kepada peserta PKH di Kecamatan Tamalate tetapi pendampinglah yang melakukan kontak langsung dengan peserta PKH.

Seperti halnya dengan bidang kesehatan, pelaksana Program
Keluarga Harapan (PKH) bidang pendidikan ini berkaitan erat dengan implementor yang terlibat secara langsung yaitu Dinas Sosial dan pendamping $\mathrm{PKH}$.

pelaksana penuh PKH bidang pendidikan di Kecamatan Tamalate adalah pendamping PKH dan Dinas Sosial. Adapun instansi-instansi terkait seperti Dinas Pendidikan dan sekolah-sekolah hanyalah sebagai mitra demi kelancaran implementasi Program Keluarga Harapan (PKH) bidang pendidikan.

Pelaksanaan PKH bidang pendidikan tidak memberikan wadah atau tempat untuk pelaksanaan program pengentasan buta huruf dan rumah belajar. Ini diakibatkan karena pendamping $\mathrm{PKH}$ Kecamatan Tamalate menganggap bahwa proses belajar di sekolah sudah cukup untuk mengentaskan anak buta huruf serta peserta PKH menganggap lebih baik bila anaknya belajar di rumah.Ini diakibatkan karena pendamping PKH Kecamatan Tamalate menganggap bahwa proses belajar di sekolah sudah cukup untuk mengentaskan anak buta huruf serta peserta $\mathrm{PKH}$ 
menganggap lebih baik bila anaknya belajar di rumah.

Pelaksanaan Program Keluarga Harapan (PKH) bidang kesehatan melibatkan beberapa aktor demi kelancaran pelaksanaan PKH bidang pendidikan di Kecamatan Tamalate. Beberapa aktor yang terlibat dalam pelaksanaan PKH adalah Dinas Sosial, Pendamping PKH, Dinas Pendidikan dan Kebudayaan, serta PT.POS/BRI. Sama halnya dengan pelaksana Program Keluarga Harapan (PKH) bidang kesehatan, yang menjadi pelaksan dalam pelaksanaan PKH bidang pendidikan adalah Dinas Sosial dan pendamping PKH Kecamatan Tamalate.

Seperti yang telah dijelaskan sebelumnya, dalam pelaksanaan PKH, Dinas Sosial berkoordinasi dengan instansi-instansi terkait seperti Dinas Pendidikan dan Kebudayaan dalam menyediakan fasilitas pendidikan untuk memenuhi kebutuhan pendidikan anak-anak KPM di Kecamatan Tamalate.

Implementasi $\mathrm{PKH}$ bidang pendidikan di Kecamatan Tamalate belum melaksanakan sebagian besar program yang telah ditentukan.
Dalam sudut pandang implementasi Program dengan menggunakan pendekatan teori model Grindle (Nugroho,2012) karakteristik lembaga pelaksana PKH bidang pendidikan di Kecamatan Tamalate belum melaksanakan tugasnya dengan maksimal. Ini disebabkan pelaksana PKH bidang pendidikan belum melaksanakan seluruh program yang telah dicangkan untuk meningkatkan kualitas pendidikan anak-anak PKM di Kecamatan Tamalate.

Elemen kepatuhan menjadi salah satu komponen penting yang mempengaruhi upaya pencapaian tujuan dari sebuah kebijakan. Kepatuhan dan daya tanggap juga merupakan bagian penting dari proses implementasi suatu kebijakan, dimana tingkat kepatuhan dan adanya respon dari para pelaksana kebijakan merupakan aksi nyata dari para pelaksana untuk melaksanakan tugas pokok dan fungsinya dalam pengimplementasian Program Keluarga Harapan (PKH) bidang pendidikan agar dapat terlaksana dengan baik secara optimal dan berdaya guna. 
Peserta PKH mengikuti apa yang dikatakan oleh pendamping PKH bukan karena mereka sadar akan pentingnya pendidikan melainkan karena mereka tidak ingin kena sanksi.Dilihat dari sudut pandang Grindle (Nugroho,2012) tingkat kepatuhan dan adanya respon dari para pelaksana kebijakan merupakan aksi nyata dari para pelaksana untuk melaksanakan tugas pokok dan fungsinya. Ini berarti tingkat kepatuhan dan daya tanggap pelaksana dan peserta PKH bidang pendidikan masih terbilang rendah.

$$
\text { Implementasi Program }
$$

Keluarga Harapan (PKH) bidang pendidikan di Kecamatan Tamalate di ukur dengan menggunakan model implementasi Grindle menunjukkan bahwa implementasi Program Keluarga Harapan (PKH) bidang pendidikan belum terimplemntasikan dengan baik. Tujuan Program Keluarga Harapan (PKH) bidang pendidikan yakni meningkatkan kualitas pendidikan anak-anak Keluarga Penerima Manfaat (KPM) dengan mencanangkan beberapa program seperti Layanan Keuangan Digital, Pengentasan anak buta huruf dan memediasi anak untuk mendaftar ke pendidikan formal, nonformal dan pendidikan luar sekolah tidak terlaksana dengan maksimal. Sehingga hal ini mempengaruhi tingkat kesadaran KPM tentang pentingnya pendidikan.

\section{KESIMPULAN}

Berdasarkan hasil penelitian tentang implementasi Program Keluarga Harapan (PKH) di kecamatan Tamalate kota Makassar maka penulis berkesimpulan bahwa:

$$
\text { Implementasi Program }
$$

Keluarga Harapan (PKH) Bidang Kesehatan dengan mengacu pada variabel isi kebijakan dan variabel lingkungan kebijakan terlaksana dengan baik. PKH bidang kesehatan telah mampu mengubah perilaku dan pola hidup sehat Keluarga Penerima Manfaat di Kecamatan Tamalate.

$$
\text { Implementasi Program }
$$

Keluarga Harapan (PKH) Bidang Pendidikan dengan mengacu pada dua variabel yakni variabel isi kebijakan dan variabel lingkungan kebijakan belum terimplementasikan dengan baik. Program-program yang dicanangkan untuk meningkatkan 
kualitas pendidikan anak-anak KPM Kecamatan Tamalate tidak dilaksanakan secara maksimal.

DAFTAR PUSTAKA

Dunn, N William, 2003. Pengantar Analisis Kebijakan Publik. Terjemahan: Wibawa Samodra, dkk. Edisi kedua cetakan kelima. Yogyakarta: Gadjah Mada University Press.

Hasibuan, Malayu, 2006. Manajemen Sumber Daya Manusia edisi revisi, Jakarta: Bumi Aksara.

Mustari Nuryanti. 2013. Implementasi Kebijakan publik.pemahaman teoritis empiris, Makassar: Membumi Publishing

Mustari, Nuryanti, 2015. Pemahaman kebijakan publik. Formulasi, implementasi dan evaluasi kebijakan publik, Yogyakarta: LeutikaPrio.

Nugroho, D. Riant, 2008. Kebijakan Publik: Formulasi, Implementasi dan Evaluasi, Jakarta: PT. Elex Media Komputindo

Nugroho, Riant, 2011. Dinamika Kebijakan, Analisis Kebijakan, Kebijakan, Manajemen Elekmedia Komputindo.

Nugroho, Riant, 2012. Publik Policy, Jakarta: PT. Gramedia
Purwanto, Erwan Agus \& Sukistyastuti, Dyah Ratih, 2012. Implementasi Kebijakan Publik, Yogyakarta: Gava Media

Tayibnapis, Farida Yusuf, 2008. Evaluasi Program dan Instrumen Evaluasi, Jakarta: PT Rineka Cipta.

Widodo, Joko, 2007. Analisis Kebijakan Publik, Malang: Bayumedia Publishing.

Winarno, Budi, 2012. Kebijakan Publik Teori, Proses, dan studi kasus, Yogyakarta: CAPS. 